\section{Kidney \\ Blood Pressure Research}

\title{
Effects of Magnoline on P-Selectin's Expression in Diabetic Rats and its Reno- Protection
}

\author{
Yang Zhou ${ }^{a}$ Feng Wang ${ }^{b}$ Lirong Hao Niansong Wang ${ }^{b}$ \\ aDepartment of Nephrology, The First Affiliated Hospital of Harbin Medical University, No.23 Youzheng \\ Street, Nangang District, Harbin 150001, China; 'Department of Nephrology, Shanghai Sixth People's \\ Hospital affiliated to Shanghai Jiaotong University, 600 Yishan Road, Shanghai 200233, China
}

\section{Key Words}

Magnoline $\cdot$ Reno-protection $・ P$-selectin $•$ Diabetic nephropathy

\begin{abstract}
Background and Objective: Magnoline is an active ingredient of magnolia fargesii with anti-inflammatory and anti-platelet effects. The objective is to explore the renoprotection of magnoline in diabetic rats and its effects on P-selectin. Methods: Thirty-six rats were randomized into 4 groups-normal control group (C), diabetic group (D), small-dose magnoline treatment group (M1) and large-dose magnoline treatment group (M2) ( $n=9$ in each group). Streptozotocin was selected to construct diabetic rat model, and group M1 and group M2 were treated with magnoline $0.5 \mathrm{mg} / \mathrm{Kg} . \mathrm{d}$ and $2 \mathrm{mg} / \mathrm{Kg} . \mathrm{d}$ respectively. Urinary albumin excretion rate, renal function, levels of P-selectin and TGF- $\beta 1$ were observed after 16 weeks. Results: Levels of albuminuria and serum creatinine of group M1 (1078.9 $\pm 77.3 \mu \mathrm{g} / 24 \mathrm{~h}$, $29.7 \pm 3.9 \mu \mathrm{mol} / \mathrm{L})$ and $\mathrm{M} 2(852.9 \pm 80.1 \mu \mathrm{g} / 24 \mathrm{~h}, 30.9 \pm 2.9 \mu \mathrm{mol} / \mathrm{L})$ were lower than group $\mathrm{D}$ $(1572.8 \pm 176.2 \mu \mathrm{g} / 24 \mathrm{~h}, 39.4 \pm 4.1 \mu \mathrm{mol} / \mathrm{L})(\mathrm{P}<0.05)$. Serum levels of P-selectin in group M1 and $\mathrm{M} 2$ were lower than group $D(P<0.05)$. The renal expression of $P$-selectin and TGF- $\beta 1$ in group M1 and M2 were significantly attenuated respectively. Conclusions: Magnoline has reno-protective effects on diabetic rats which may be related to the inhibition of P-selectin.
\end{abstract}

Copyright (C) 2013 S. Karger AG, Basel

\section{Introduction}

Nowadays chronic kidney disease (CKD) has become a serious public health problem and a severe threat to human health [1-2]. In recent years, secondary renal disease has gradually become the main cause leading to end stage renal diseases (ESRD). Among all 


\section{Kidney \\ Blood Pressure Research}

the microvascular complications diabetic nephropathy (DN) is the specific complication of diabetes (DM) with the greatest mortality [3]. In developed countries, $40 \%$ of ESRD is caused by DN, and a similar trend comes to occur in developing countries [4-5].

The pathogenesis of DN is quite complicated, and thus becomes a popular topic in today's CKD research. Recently it is believed that DM is a chronic inflammatory disease, and antiinflammation may prevent the progression of the complications such as DN [6-7]. Studies have shown that P-selectin may be involved in the pathogenesis of $\mathrm{DN}$, and may become a novel target of DN therapy [8-9]. As a result, looking for drugs effective to DN immediately turns into a mission of nephrologists.

Magnoliae fargesii, a herbal medicine was found it has wide range of pharmacological effects, including lowering blood pressure, anti-bacterial, anti-inflammatory and anti-allergic effects, in which the anti-inflammatory effect is taken seriously in particular. Magnoline is one of the important active ingredients of Magnoliae fargesii volatile oil [10]. It is unknown whether magnoline has anti-inflammatory effects on DN. In this work Streptozotocin (STZ) induced diabetic rat model was utilized to study the changes of P-selectin and the renoprotective effects of magnoline.

\section{Materials and Methods}

\section{Animals and reagents}

Thirty-six healthy male SD rats, weighing $250 \pm 20$ g, were from Shanghai Laboratory Animal Center, Chinese Academy of Sciences. STZ (Sigma) was dissolved in $0.1 \mathrm{~mol} / \mathrm{L} \mathrm{pH} 4.6$ citrate buffer and magnoline (Shanghai Oriental Medicine) was dissolved in 0.9\% saline before used. ELISA Kit for the determination of P-selectin, ICAM-1 and CRP was provided by Shanghai Immune Biotech, China. Rabbit anti-P-selectin monoclonal antibody, TGF- $\beta 1$ monoclonal antibody and HRP-conjugated goat anti-rabbit IgG secondary antibody were provided by Shanghai Immune Biotech, China.

\section{Animal model construction}

Random number table method was adopted to divide the experimental animals into 4 groups —normal control group (C), diabetic group (D), small-dose magnoline treatment group (M1) and large-dose magnoline treatment group (M2) (n=9 in each group). Group D, M1 and M2 were given intraperitoneal injection of STZ at a dose of $55 \mathrm{mg} / \mathrm{Kg}$. Then tail vein blood was collected $72 \mathrm{~h}$ later, and fasting plasma glucose (FPG) was determined. FPG $\geq 16.7 \mathrm{mmol} / \mathrm{L}$ was taken as the criterion to determine whether the type $2 \mathrm{DM}$ rat model was successful. Group C received intraperitoneal injection of the same volume of citrate buffer. Magnoline was dissolved in $0.9 \%$ saline to reach the final concentration of $0.25 \mathrm{mg} / \mathrm{ml}$. Rats in group M1 and group M2 were treated with $0.5 \mathrm{mg} / \mathrm{Kg} . \mathrm{d}$ and $2 \mathrm{mg} / \mathrm{Kg}$.d magnoline by tail vein injection respectively. Rats in group C and $\mathrm{D}$ were treated with the $0.9 \%$ saline. All animals were given normal diets and free water consumption, and sacrificed in the 16 th week.

\section{Indicators determination}

Two days before the rats were sacrificed, metabolic cages were used to collect $24 \mathrm{~h}$ urine for the determination of urine albumin excretion rate (UAER). ELISA method was employed for the determination of serum P-selectin, ICAM-1 and CRP, while blood glucose (BG), triglycerides (TG), total cholesterol (TC), blood urea nitrogen (BUN), serum creatinine ( $\mathrm{SCr}$ ), urinary creatinine and other biochemical indicators were determined with an automatic biochemical analyzer. Then the creatine clearance (CCr) was calculated. HPLC method was adopted for the determination of HbA1c. TRIzol was applied to extract mRNA, and realtime RT-PCR detection of P-selectin mRNA expression in the renal cortex was carried out. The sequence of P-selectin primers were: F 5'-GCATACTCATGGAATAACTCACG -3, R 5'-GACGTCATTGAGGTGAGCG-3', and the sequence of internal control GAPDH primers were: $F$ 5'-CCGAGGGCCCACTAAAGG-3', R 5'-GCTGTTGAAGTCACAGGAGACAA-3'. 


\section{Kidney Blood Pressure Research}

Renal histological study

Renal tissues were collected for light microscopy and electron microscopy. The pathological changes including levels of mesangial area and foot process effacement in each group were compared. TGF- $\beta 1$ and P-selectin expression in renal cortex were determined by using SABC immunohistochemical methods and western blot. Western blot analysis was performed with anti-P-selectin and anti-TGF- $\beta 1$ antibody. Membranes were stained with Coomassie blue, and the total Coomassie blue intensity in each lane was used for normalization [11].

\section{Statistical analysis}

Data were expressed as means \pm SD and SPSS18.0 software was employed for data analysis. Multiple comparisons of normally distributed data were analyzed by ANOVA. A value of $P<0.05$ was considered statistically significant.

\section{Results}

Blood glucose and lipid metabolism parameters in diabetic rats

The results showed that the BG and HbA1c in groups D, M1 and M2 were significantly higher than group $C(P<0.05)$, while there was no significant difference among groups $D, M 1$ and M2 $(P>0.05)$. TG and TC in group D were significantly higher than group $\mathrm{C}$, while TG and TC levels in group M1 and M2 were lower than group D $(P<0.05)$, but there was no statistic difference between group M1 and M2 $(P>0.05)$ as shown in Table 1.

\section{Magnoline attenuated kidney injury}

Body weights of the rats in groups D, M1 and M2 were significantly lower than group C $(P<0.05)$. Compared with group $\mathrm{D}$, kidney weight/body weight ratios in group M1 and M2 were lower $(P<0.05)$, but there was no difference between the two groups $(P>0.05)$. BUN and $\mathrm{SCr}$ in groups D, M1 and M2 were significantly higher than group C $(P<0.05)$. Compared with group D, BUN and SCr in group M1 and M2 were lower $(P<0.05)$, but there was no difference between the two groups $(P>0.05)$ (Table 2). CCr in group M1 and M2 were higher significantly than group D $(P<0.05)$ as shown in Fig. 1. UAER in groups D, M1 and M2 was significantly higher than group $C(P<0.05)$. Compared with group D $(1572.8 \pm 176.2 \mu \mathrm{g} / 24 \mathrm{~h})$, UAER in group M1 $(1078.9 \pm 77.3 \mu \mathrm{g} / 24 \mathrm{~h})$ and group M2 $(852.9 \pm 80.1 \mu \mathrm{g} / 24 \mathrm{~h})$ was lower $(P<0.05)$, and UAER in group M2 was even lower than group M1 $(P<0.05)$ as shown in Fig. 1.

\section{Magnoline reduced renal histological damage}

Compared with group $\mathrm{C}$, diabetic rats in group D had wider mesangial area $(P<0.05)$, with increased mesangial cell proliferation in individual segments and matrix. Compared with group D, rats treated with magnoline (group M1 and M2) had less mesangial area $(P<0.05)$ and matrix as shown in Fig. 2. Under electron microscope compared with group $\mathrm{C}$, diabetic rats in group $\mathrm{D}$ had increased mesangial matrix, thickened basement membrane and wider foot process effacement $(P<0.05)$. Compared with group $\mathrm{D}$, rats treated with magnoline (group M1 and M2) had less mesangial matrix and less foot process effacement $(P<0.05)$ as shown in Fig. 3.

\section{Magoline inhibited the expression of P-selectin, ICAM-1 and CRP}

Through correlation analysis, serum P-selectin and ICAM-1, CRP, UAER, and SCr were positively correlated as illustrated in Table $3(P<0.05)$. Compared with group $\mathrm{C}$, the expression of serum P-selectin (Fig. 4-A), P-selectin mRNA in renal cortex (Fig. 4-B), serum ICAM-1 (Fig. 4-C) and CRP (Fig. 4-D) in group D increased significantly $(P<0.05)$. Compared with group D levels of P-selectin, ICAM-1 and CRP in group M1 and group M2 decreased significantly $(P<0.05)$. 


\section{Kidney \\ Blood Pressure Research}

Table 1. Changes in blood glucose and lipids $(\bar{\chi} \pm$ SD)

\begin{tabular}{cccccc}
\hline Group & $\mathrm{n}$ & $\mathrm{BG}(\mathrm{mmol} / \mathrm{L})$ & HbA1c $(\%)$ & TG $(\mathrm{mmol} / \mathrm{L})$ & TC $(\mathrm{mmol} / \mathrm{L})$ \\
\hline C & 9 & $4.6 \pm 0.6$ & $5.1 \pm 0.6$ & $0.38 \pm 0.11$ & $1.22 \pm 0.14$ \\
D & 9 & $20.1 \pm 2.2^{*}$ & $9.8 \pm 1.0^{*}$ & $0.91 \pm 0.06^{*}$ & $1.77 \pm 0.15^{*}$ \\
M1 & 9 & $20.2 \pm 2.3^{*}$ & $9.0 \pm 0.9^{*}$ & $0.68 \pm 0.13^{\#}$ & $1.46 \pm 0.08^{\#}$ \\
M2 & 9 & $21.1 \pm 2.3^{*}$ & $9.1 \pm 0.8^{*}$ & $0.72 \pm 0.11^{\#}$ & $1.47 \pm 0.18^{\#}$ \\
\hline
\end{tabular}

Table 2. Renal injury-related parameters $(\bar{\chi} \pm$ SD $)$

\begin{tabular}{cccccccc}
\hline Group & $\mathrm{n}$ & BW (g) & KW(g) & $\begin{array}{c}\text { KW/BW } \\
(\% 0)\end{array}$ & UV(ml/24h) & $\begin{array}{c}\text { BUN } \\
(\mathrm{mmol} / \mathrm{L})\end{array}$ & $\begin{array}{c}\mathrm{SCr} \\
(\mu \mathrm{mol} / \mathrm{L})\end{array}$ \\
\hline C & 9 & $502.8 \pm 33.6$ & $1.51 \pm 0.09$ & $3.0 \pm 0.2$ & $46.4 \pm 10.3$ & $6.1 \pm 0.6$ & $25.3 \pm 4.3$ \\
D & 9 & $331.4 \pm 19.4^{*}$ & $1.73 \pm 0.13^{*}$ & $5.2 \pm 0.4^{*}$ & $142.2 \pm 19.6^{*}$ & $11.9 \pm 1.0^{*}$ & $39.4 \pm 4.1^{*}$ \\
M1 & 9 & $380.3 \pm 33.0^{\#}$ & $1.63 \pm 0.12$ & $4.3 \pm 0.4^{\#}$ & $144.5 \pm 18.9$ & $9.4 \pm 0.6^{\#}$ & $29.7 \pm 3.9^{\#}$ \\
M2 & 9 & $391.2 \pm 29.6^{\#}$ & $1.68 \pm 0.15$ & $4.3 \pm 0.4^{\#}$ & $150.3 \pm 21.4$ & $9.7 \pm 0.9^{\#}$ & $30.9 \pm 2.9^{\#}$ \\
\hline
\end{tabular}

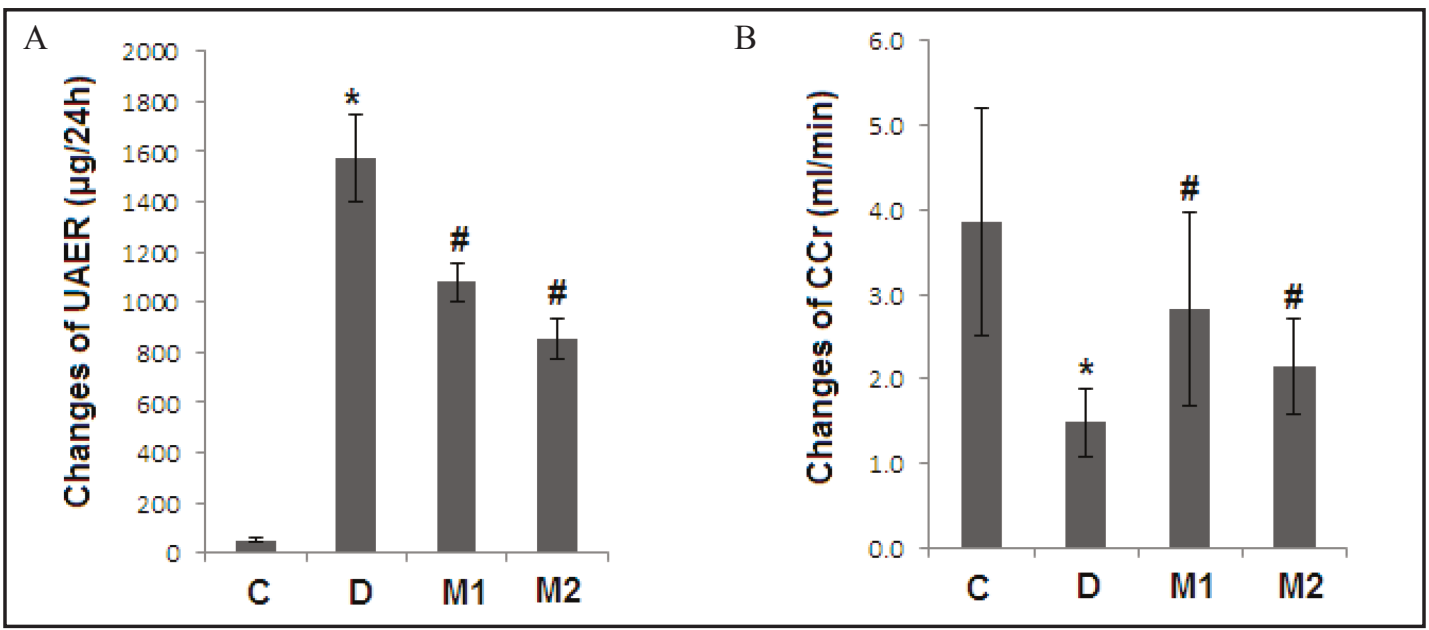

Fig. 1. Magnoline reduced the albuminuria and protected the creatinine clearance in diabetic rats. Changes of UAER (A). Changes of CCr (B). C, normal control group, n=9; D, STZ-induced diabetic rats, n=9; M1, diabetic rats treated with magnoline $(0.5 \mathrm{mg} / \mathrm{kg}), \mathrm{n}=9 ; \mathrm{M} 2$, diabetic rats treated with magnoline $(2 \mathrm{mg} / \mathrm{kg}), \mathrm{n}=9$. ${ }^{*} P<0.05$ vs group C. \#P<0.05 vs group D.

Magoline ameliorated P-selectin and TGF- $\beta 1$ expression in renal tissues

The results showed that the expression of P-selectin and TGF- $\beta 1$ in rat glomeruli of group $C$ was very weak, while enormous expression in group D could be observed by using immunohistological staining and western blot. Compared with group D the renal expression of P-selectin and TGF- $\beta 1$ were attenuated in group M1 and M2 as shown in Fig. 5-7 $(P<0.05)$.

\section{Discussion}

DN is the most common secondary renal disease, one of the microvascular complications of DM, and one of the most crucial death causes of DM [12]. Thus, mechanism and prevention research on DN is one of the most important fields of life sciences [13-14].

DN, in essence, is a microvascular disease caused by DM, whose basic pathological changes include glomerular hypertrophy, accumulation of extracellular matrix, basement membrane thickening and glomerular sclerosis. Extensive infiltration of monocytes or 


\section{Kidney \\ Blood Pressure \\ Research}

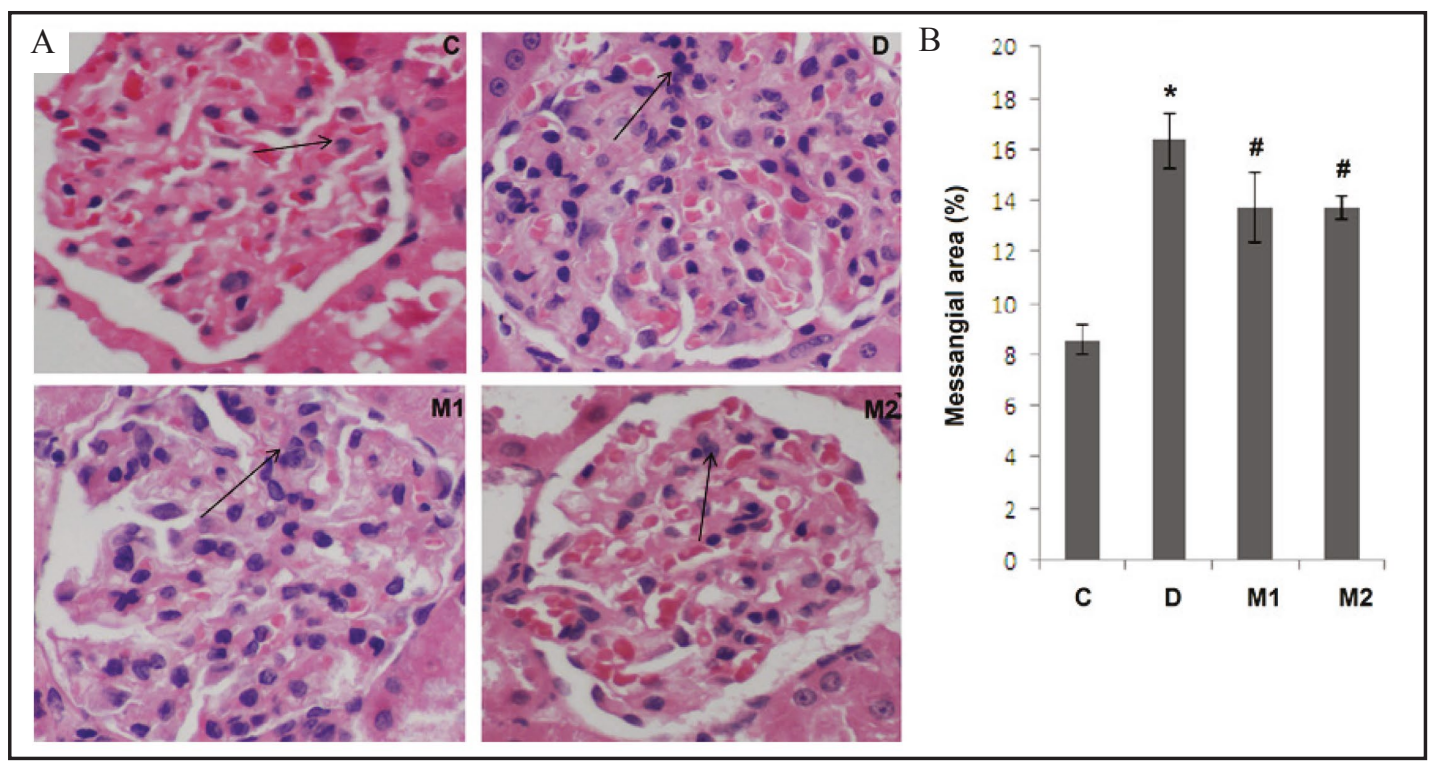

Fig. 2. Magnoline reduced renal histological damage under lightscope (HE 400×). Representative hematoxylin and eosin staining of glomeruli from each group (A). Semi-quantitive analysis of mean messangial area from each group (B). C, normal control group, n=9; D, STZ-induced diabetic rats, $n=9$; M1, diabetic rats treated with magnoline $(0.5 \mathrm{mg} / \mathrm{kg}), \mathrm{n}=9 ; \mathrm{M} 2$, diabetic rats treated with magnoline $(2 \mathrm{mg} / \mathrm{kg}), \mathrm{n}=9 .{ }^{*} P<0.05$ vs group C. $\# P<0.05$ vs group $\mathrm{D}$.

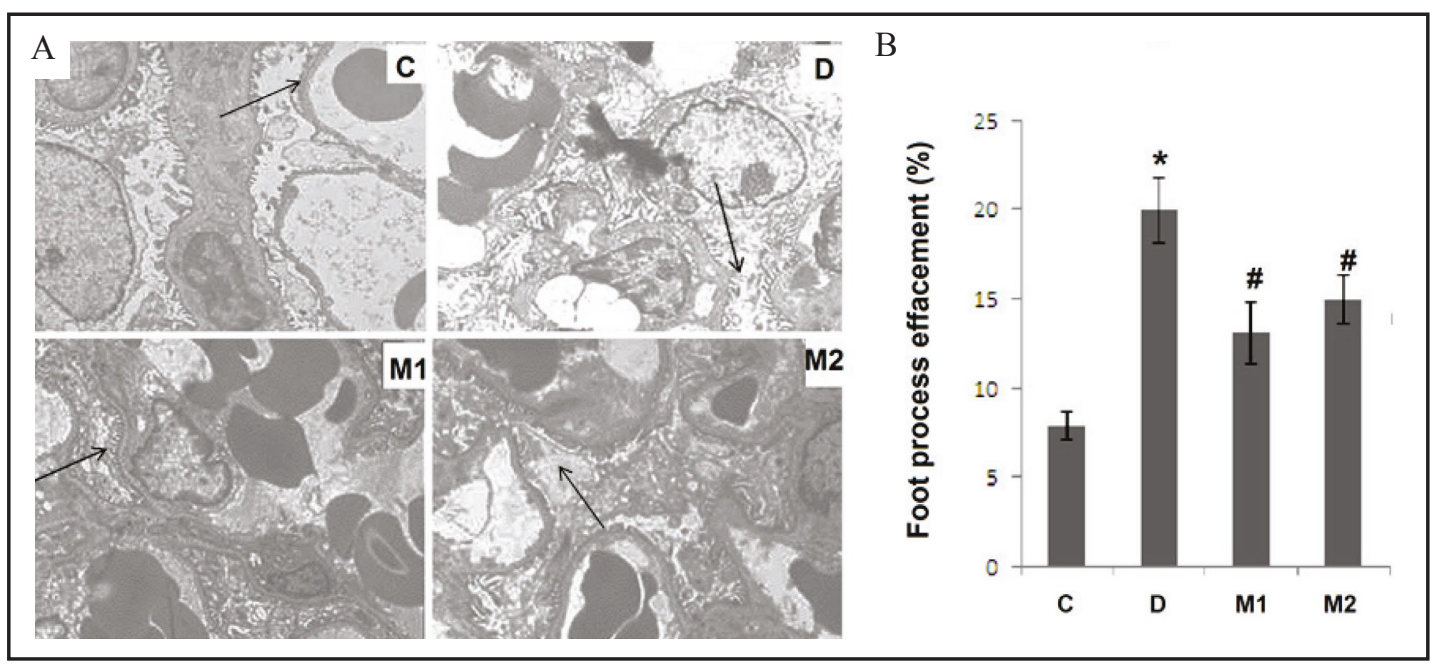

Fig. 3. Magnoline reduced renal histological damage under electron (4000×). Representative electron photomicrographs of glomeruli from each group (A). Semi-quantitive analysis of foot process effacement from each group (B). C, normal control group, n=9; D, STZ-induced diabetic rats, $n=9 ;$ M1, diabetic rats treated with magnoline $(0.5 \mathrm{mg} / \mathrm{kg}), \mathrm{n}=9 ; \mathrm{M} 2$, diabetic rats treated with magnoline $(2 \mathrm{mg} / \mathrm{kg}), \mathrm{n}=9 .{ }^{*} P<0.05$ vs group C. $\# P<0.05$ vs group $\mathrm{D}$.

macrophages in glomeruli is a histological characteristic of DN progression, and is also a basis supporting DN as an inflammatory disease [15]. With the rapid development of cell biology and molecular biology and the deeper understanding of inflammation, the concept of inflammation has gradually been updated [16-17]. More evidence has shown that diabetic nephropathy is an inflammatory disease just like other glomerular diseases. The activation of cell adhesion molecules, co-stimulatory molecules, cytokines and platelet is involved in the occurrence and development of diabetic complications $[7,8,10,18]$. 


\section{Kidney Blood Pressure Research}

Fig. 4. Magoline inhibited the expression of P-selectin, ICAM-1 and CRP. Serum levels of P-selectin (A). Renal cortex expression of P-selectin mRNA (B). Serum levels of ICAM-1 (C). Serum levels of CRP (D). C, normal control group, $n=9 ; D$, STZ-induced diabetic rats, $\mathrm{n}=9$; M1, diabetic rats treated with magnoline $(0.5 \mathrm{mg} /$ $\mathrm{kg}$ ), $\mathrm{n}=9$; $\mathrm{M} 2$, diabetic rats treated with magnoline $(2 \mathrm{mg} / \mathrm{kg}), \mathrm{n}=9 .{ }^{*} P<0.05$ vs group $\mathrm{C}, \# P<0.05$ vs group D.

Table 3. Correlations between Serum P-selectin and other parameters

\begin{tabular}{ccc}
\hline & \multicolumn{2}{c}{ P-selectin } \\
& $\mathrm{R}^{2}$ & $\mathrm{P}$ \\
\hline ICAM-1 & 0.69 & $P<0.01$ \\
CRP & 0.61 & $P<0.01$ \\
UAER & 0.53 & $P<0.01$ \\
SCr & 0.36 & $P<0.01$ \\
\hline
\end{tabular}

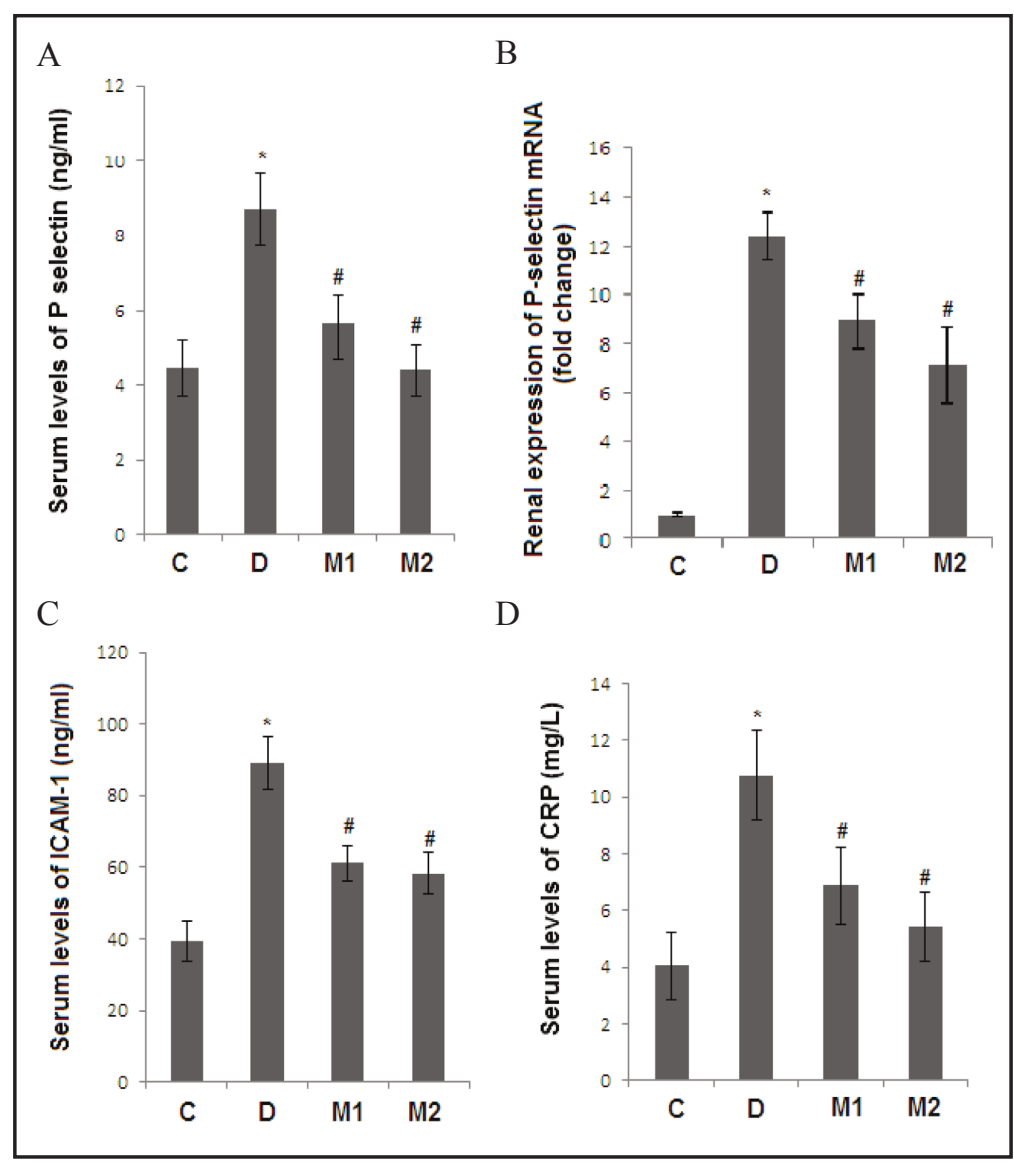

As an important member of selectins, P-selectin is a sign of endothelial cells' and platelets' activation, playing an essential role in the occurrence of a variety of inflammatory diseases [19-20]. It is currently considered that P-selectin and its mediated endothelial injury and platelet aggregation are involved in the development of DN [21]. High blood glucose can lead to enormous P-selectin expression in endothelial cells and enhanced P-selectinmediated leukocyte adhesion. Insulin can contribute to the inhibition of the above effects. The microvascular disease of DM is related to P-selectin-mediated cell adhesion, thrombosis and promoted inflammation [22]. Hyperglycemia stimulates glomerular mesangial cells to secrete monocyte chemoattractant protein-1, which may induce monocytes and macrophages to interact with P-selectin on the surface of endothelial cells and eventually trans-differentiate into foam cells, thereby causing irreversible glomerular sclerosis. Previous studies have found that P-selectin is closely related to glomerular sclerosis and interstitial fibrosis of DN [23-24]. Another study has shown that P-selectin gene polymorphism may be in line with DN [25]. Anti-P-selectin treatment has demonstrated significant anti-inflammatory effects, with preventive effects on a variety of acute and chronic inflammatory diseases, whose mechanism is the inhibition of the normal combination of P-selectin and its ligands [26]. This research found that P-selectin in the serum and kidney tissue of STZ-induced diabetic rats were significantly higher than normal controls which is consistent with the literature results [27-28], and has once again proved that P-selectin is involved in the pathogenesis of DN [29]. Besides, it was found that magnoline could significantly decrease serum lipids and UAER in diabetic rats, reduce renal hypertrophy (kidney weight/body weight ratio), mitigate renal pathological changes, and protect renal function. At the same time, the results showed that both large and small doses of magnoline significantly inhibited P-selectin expression in serum and renal tissue, and reduced renal levels of TGF- $\beta 1$. Therefore, it can be inferred that 


\section{Kidney Blood Pressure Research}

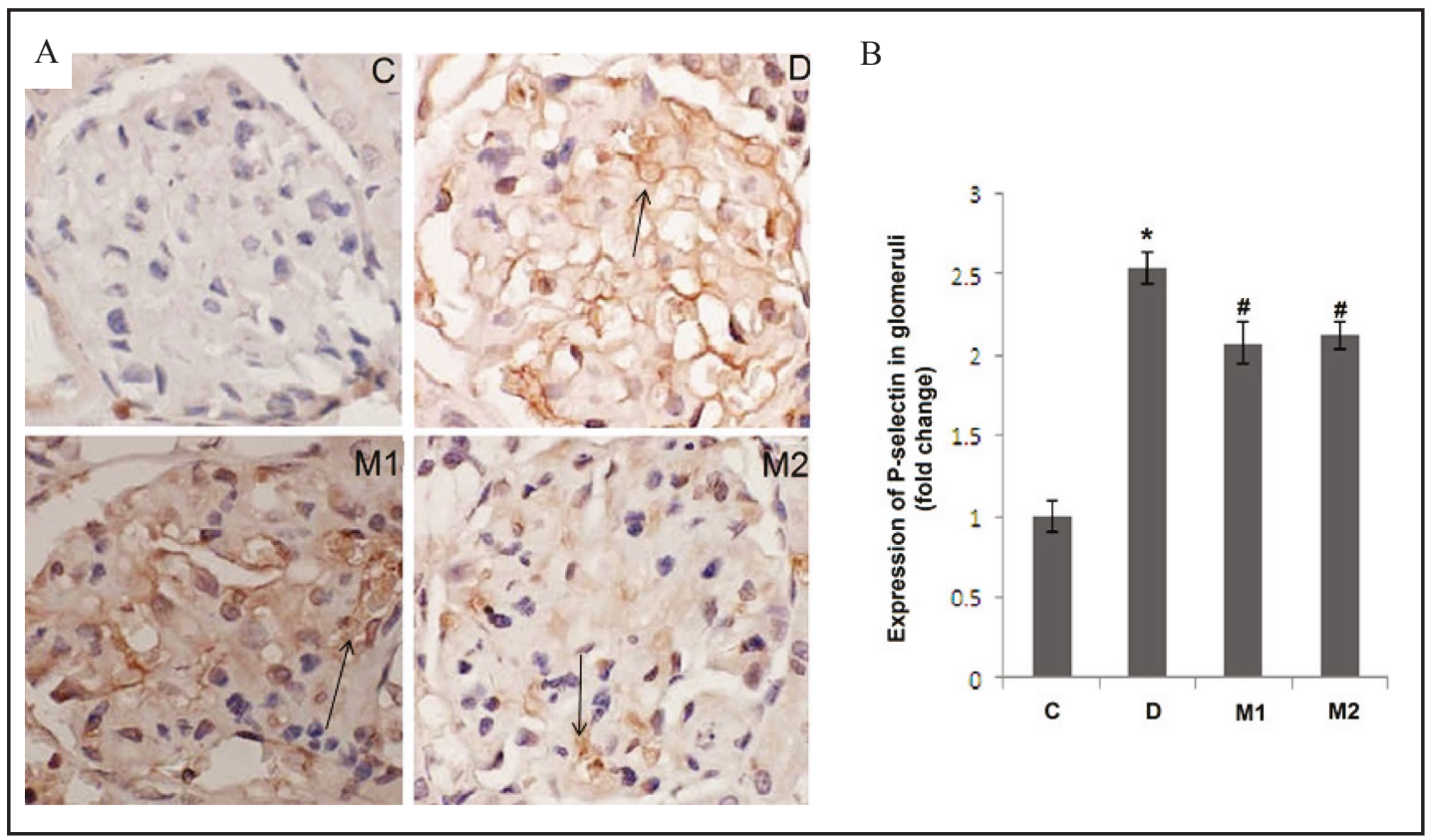

Fig. 5. Magoline ameliorated P-selectin expression in glomeruli (400×). Representative immunohistochemical staining of P-selectin in glomeruli from each group (A). Semi-quantitive analysis of P-selectin expression in glomeruli from each group (B). C, normal control group, n=9; D, STZ-induced diabetic rats, n=9; M1, diabetic rats treated with magnoline $(0.5 \mathrm{mg} / \mathrm{kg}), \mathrm{n}=9 ; \mathrm{M} 2$, diabetic rats treated with magnoline $(2 \mathrm{mg} / \mathrm{kg}), \mathrm{n}=9$. $* P<0.05$ vs group C. $\# P<0.05$ vs group D.

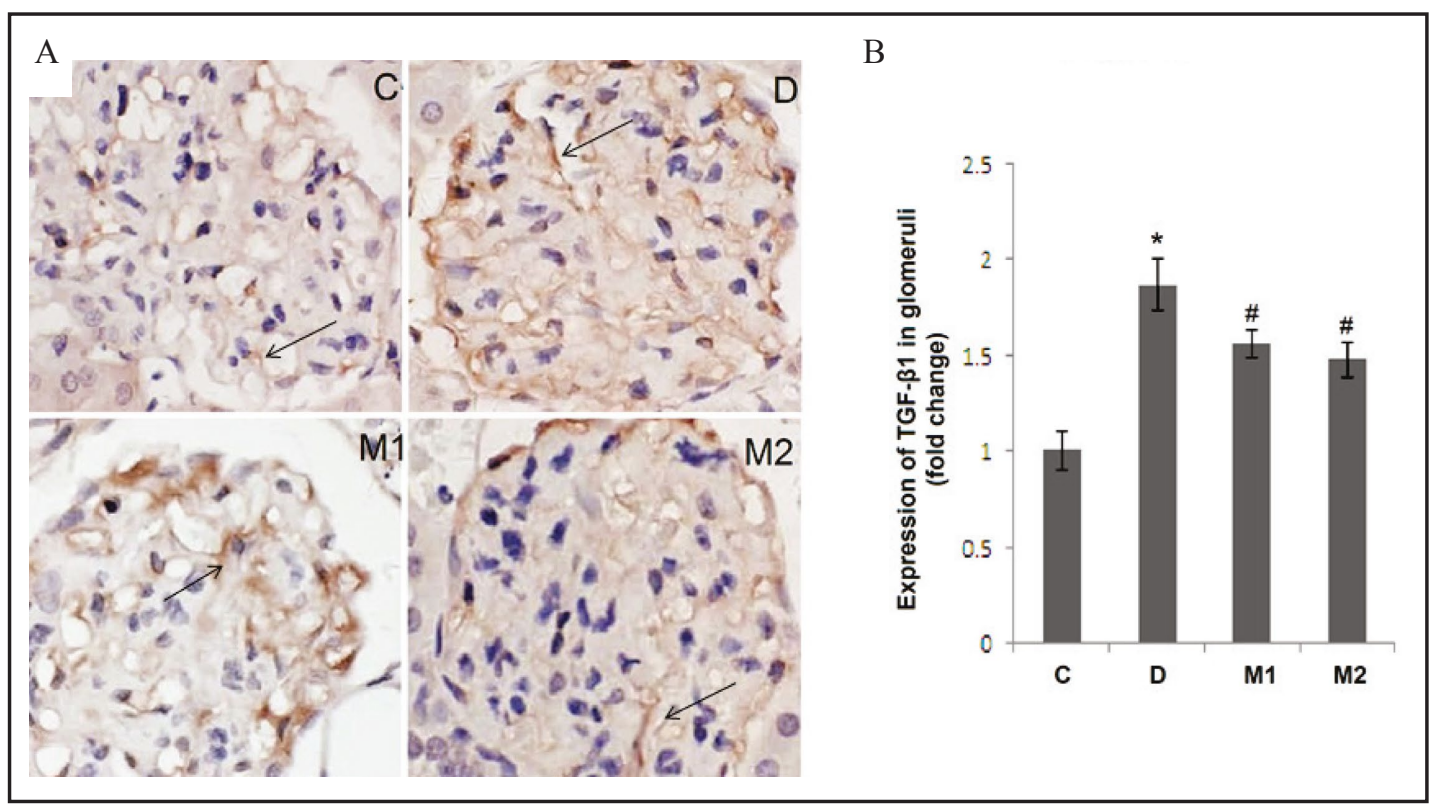

Fig. 6. Magoline ameliorated TGF- $\beta 1$ expression in glomeruli (400×). Representative immunohistochemical staining of TGF- $\beta 1$ in glomeruli from each group (A). Semi-quantitive analysis of TGF- $\beta 1$ expression in glomeruli from each group (B). C, normal control group, n=9; D, STZ-induced diabetic rats, n=9; M1, diabetic rats treated with magnoline $(0.5 \mathrm{mg} / \mathrm{kg}), \mathrm{n}=9 ; \mathrm{M} 2$, diabetic rats treated with magnoline $(2 \mathrm{mg} / \mathrm{kg}), \mathrm{n}=9$. ${ }^{*} P<0.05$ vs group C. $\# P<0.05$ vs group D. 


\section{Kidney Bloód Pressure Research}

Fig. 7. Magoline ameliorated P-selectin and TGF- $\beta 1$ expression in renal cortex. Representative immunohistochemical staining of P-selectin and TGF- $\beta 1$ in renal cortex from each group (A). Semi-quantitive analysis of P-selectin and TGF- $\beta 1$ expression in cortex from each group (B). C, normal control group; D, STZ-induced diabetic rats; M1, diabetic rats treated with magnoline $(0.5 \mathrm{mg} / \mathrm{kg})$; M2, diabetic rats treated with magnoline (2mg/ $\mathrm{kg}$ ). ${ }^{*} P<0.05$ vs group $\mathrm{C}$, $\# P<0.05$ vs group $\mathrm{D}$.

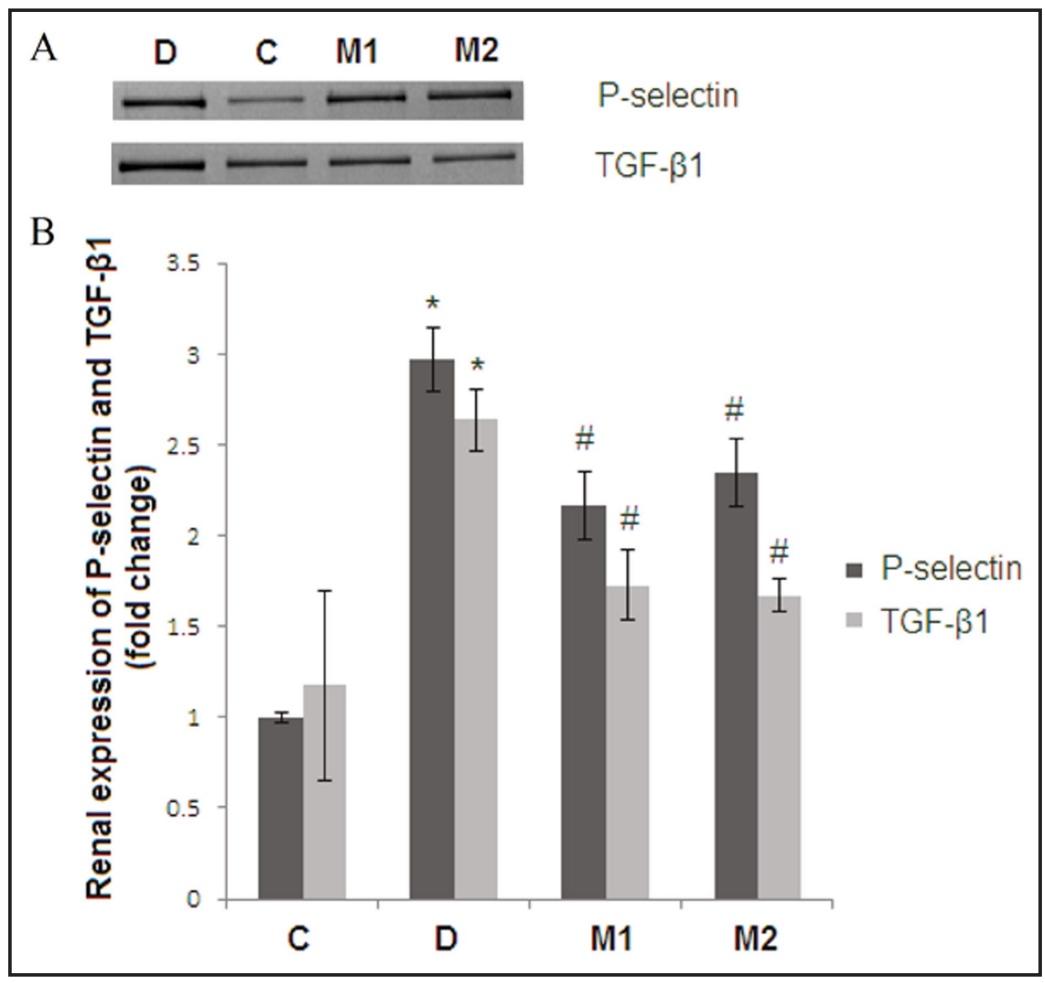

the renoprotective effect of magnoline may be related to the anti-inflammatory effects of the inhibition of P-selectin [30].

Literatures have reported that P-selectin is closely related to lipid metabolism disorders and atherosclerosis [31-32]. This study found that the inhibition of P-selectin expression by magnoline was associated with decreased blood lipids. Whether it was the result or cause of the protection of renal function is unclear, and the specific mechanism needs further study. At present, many researches aim to find anti-inflammatory drugs with antagonistic effects on P-selectin, and have achieved some good results [33].

Our group found that volatile oil of Magnolia biondii had anti-inflammatory effect in rat model with diabetic nephropathy [34]. But volatile oil of Magnolia biondii is a mixture composing of a lot of ingredients. This research indicated that magnoline has protective effect on kidney damage in DN rats, which is in line with previous studies. However, magnoline with anti-inflammatory and anti-platelet effects has extensive pharmacological activity, whose molecular mechanism is complex [35-36]. Therefore, the mechanism of magnoline for reno-protection in diabetic rats still needs further research. If the molecular mechanism of magnoline in the treatment of diabetic nephropathy is demonstrated, it will serve as a good choice and a different way for the anti-inflammatory treatment of DN.

\section{Conflict of Interests}

The authors have no interests to disclose.

\section{Acknowledgements}

The work is supported by national scientific foundation of China (No. 81100528 and No. 81270824). Thanks to Prof. Zhigang Zhang for his help in histological study. Dr. Yang Zhou and Dr. Feng Wang contributed to this work equally. 


\section{Kidney \\ Blood Pressure Research}

\section{References}

1 Kovesdy CP, Kalantar-Zadeh K: Enter the dragon: a Chinese epidemic of chronic kidney disease? Lancet 2012;379:783-785.

2 Mangione F, Dal Canton A: Chronic kidney disease epidemic: myth and reality. Intern Emerg Med 2011;6:69-76.

-3 Farag YM, Al Wakeel JS: Diabetic nephropathy in the Arab Gulf countries. Nephron Clin Pract 2011;119:c317-322.

-4 Campbell GA, Bolton WK: Referral and comanagement of the patient with CKD. Adv Chronic Kidney Dis 2011;18:420-427.

-5 Zhang L, Wang F, Wang L, Wang W, Liu B, Liu J, Chen M, He Q Liao Y, Yu X, Chen N, Zhang JE, Hu Z, Liu F, Hong D, Ma L, Liu H, Zhou X, Chen J, Pan L, Chen W, Wang W, Li X, Wang H: Prevalence of chronic kidney disease in China: a cross-sectional survey. Lancet 2012;379:815-822.

6 Wu CC, Sytwu HK, Lu KC, Lin YF: Role of T cells in type 2 diabetic nephropathy. Exp Diabetes Res 2011;2011:514738.

7 Wu CC, Sytwu HK, Lin YF: Cytokines in diabetic nephropathy. Adv Clin Chem 2012;56:55-74.

8 Tarnow I, Michelson AD, Barnard MR, Frelinger AL 3rd, Aasted B, Jensen BR, Parving HH, Rossing P, Tarnow L: Nephropathy in type 1 diabetes is associated with increased circulating activated platelets and platelet hyperreactivity. Platelets 2009;20:513-519.

9 Wang F, Xing T, Wang N, Liu L: Clinical significance of plasma CD146 and P-selectin in patients with type 2 diabetic nephropathy. Cytokine 2012;57:127-129.

10 Ahn KS, Jung KY, Kim JH, Oh SR, Lee HK: Inhibitory activity of lignan components from the flower buds of Magnoliae fargesii on the expression of cell adhesion molecules. Biol Pharm Bull 2001;24:1085-1087.

-11 Usa K, Singh RJ, Netzel BC, Liu Y, Raff H, Liang M: Renal interstitial corticosterone and 11-dehydrocorticosterone in conscious rats. Am J Physiol Renal Physiol 2007;293:F186-F192.

-12 Najafian B, Alpers CE, Fogo AB: Pathology of human diabetic nephropathy. Contrib Nephrol 2011;170:3647.

-13 Navarro-González JF, Mora-Fernández C, Muros de Fuentes M, García-Pérez J: Inflammatory molecules and pathways in the pathogenesis of diabetic nephropathy. Nat Rev Nephrol 2011;7:327-340.

14 Thomas MC: Advanced glycation end products. Contrib Nephrol 2011;170:66-74.

15 Kelly KJ, Dominguez JH: Rapid progression of diabetic nephropathy is linked to inflammation and episodes of acute renal failure. Am J Nephrol 2010;32:469-475.

16 Nathan C: Points of control in inflammation. Nature 2002;420:846-852.

17 Tracey KJ: The inflammatory reflex. Nature 2002;420:853-859.

-18 Angiolillo DJ, Bernardo E, Capodanno D, Vivas D, Sabaté M, Ferreiro JL, Ueno M, Jimenez-Quevedo P, Alfonso F, Bass TA, Macaya C, Fernandez-Ortiz A: Impact of chronic kidney disease on platelet function profiles in diabetes mellitus patients with coronary artery disease taking dual antiplatelet therapy. J Am Coll Cardiol 2010;55:1139-1146.

19 Cerletti C, Tamburrelli C, Izzi B, Gianfagna F, de Gaetano G: Platelet-leukocyte interactions in thrombosis. Thromb Res 2012: 129:263-266.

-20 Binder FP, Ernst B: E- and P-selectin: differences, similarities and implications for the design of P-selectin antagonists. Chimia (Aarau) 2011;65:210-213.

-21 Goldberg RB: Cytokine and cytokine-like inflammation markers, endothelial dysfunction, and imbalanced coagulation in development of diabetes and its complications. J Clin Endocrinol Metab 2009;94:3171-3182.

22 Booth G, Stalker TJ, Lefer AM, Scalia R: Elevated ambient glucose induces acute inflammatory events in the microvasculature: effects of insulin. Am J Physiol Endocrinol Metab 2001;280:E848-E856.

23 Hirata K, Shikata K, Matsuda M, Akiyama K, Sugimoto H, Kushiro M, Makino H: Increased expression of selectins in kidneys of patients with diabetic nephropathy. Diabetologia 1998;41:185-192.

24 Omoto S, Nomura S, Shouzu A, Hayakawa T, Shimizu H, Miyake Y, Yonemoto T, Nishikawa M, Fukuhara S, Inada M: Significance of platelet-derived microparticles and activated platelets in diabetic nephropathy. Nephron 1999;81:271-277. 


\section{Kidney \\ Blood Pressure Research}

Zhou/Wang/Hao/Wang: Reno-Protection of Magnoline on Diabetic Rats

-25 Liu Y, Burdon KP, Langefeld CD, Beck SR, Wagenknecht LE, Rich SS, Bowden DW, Freedman BI: P-selectin gene haplotype associations with albuminuria in the Diabetes Heart Study. Kidney Int 2005;68:741-746.

26 Wang JG, Geng JG: Affinity and kinetics of P-selectin binding to heparin. Thromb Haemost 2003;90:309316.

27 Bavbek N, Kargili A, Kaftan O, Karakurt F, Kosar A, Akcay A: Elevated concentrations of soluble adhesion molecules and large platelets in diabetic patients: are they markers of vascular disease and diabetic nephropathy? Clin Appl Thromb Hemost 2007;13:391-397.

-28 Nomura S, Shouzu A, Omoto S, Nishikawa M, Iwasaka T, Fukuhara S: Activated platelet and oxidized LDL induce endothelial membrane vesiculation: clinical significance of endothelial cell-derived microparticles in patients with type 2 diabetes. Clin Appl Thromb Hemost 2004;10:205-215.

-29 Iwamoto M, Mizuiri S, Arita M, Hemmi H: Nuclear factor-kappaB activation in diabetic rat kidney: evidence for involvement of P-selectin in diabetic nephropathy. Tohoku J Exp Med 2005;206:163-171.

-30 Wu K, Zhou T, Sun G, Wang W, Zhang Y, Zhang Y, Hao L, Chen N: Valsartan inhibited the accumulation of dendritic cells in rat fibrotic renal tissue. Cell Mol Immunol 2006;3:213-220.

- 31 Georgescu A, Alexandru N, Andrei E, Titorencu I, Dragan E, Tarziu C, Ghiorghe S, Badila E, Bartos D, Popov D: Circulating microparticles and endothelial progenitor cells in atherosclerosis: pharmacological effects of irbesartan. J Thromb Haemost 2012;10:680-691.

- 32 Phillips JW, Barringhaus KG, Sanders JM, Hesselbacher SE, Czarnik AC, Manka D, Vestweber D, Ley K, Sarembock IJ: Single injection of P-selectin or P-selectin glycoprotein ligand-1 monoclonal antibody blocks neointima formation after arterial injury in apolipoprotein E-deficient mice. Circulation 2003;107:22442249.

33 Wan JG, Mu JS, Zhu HS, Geng JG: N-desulfated non-anticoagulant heparin inhibits leukocyte adhesion and transmigration in vitro and attenuates acute peritonitis and ischemia and reperfusion injury in vivo. Inflamm Res 2002;51:435-443.

-34 Sun XP, Wang NS, Xue Q, Wang F: Volatile oil of Magnolia biondii inhibits expressions of P-selectin protein in serum and renal tissue of rats with diabetic nephropathy. Zhong Xi Yi Jie He Xue Bao 2008;6:524-529.

35 Kim JY, Lim HJ, Lee da Y, Kim JS, Kim do H, Lee HJ, Kim HD, Jeon R, Ryu JH: In vitro anti-inflammatory activity of lignans isolated from Magnolia fargesii. Bioorg Med Chem Lett 2009;19:937-940.

-36 Baek JA, Lee YD, Lee CB, Go HK, Kim JP, Seo JJ, Rhee YK, Kim AM, Na DJ: Extracts of Magnoliae flos inhibit inducible nitric oxide synthase via ERK in human respiratory epithelial cells. Nitric Oxide 2009;20:1221228. 